\title{
$\mathrm{PVOH}$ 와 polyDADMAC 첨가에 의한 산화전분의 표면사이징 효과 변화
}

\author{
서동일·정영빈·정광호·이학래 ${ }^{\dagger} \cdot$ 윤혜정
}

접수일(2013년 7월 2일), 수정일(2013년 7월 24일), 채택일(2013년 7월 30일)

\section{Effect of PVOH or polyDADMAC Addition on Surface Sizing with Oxidized Starch}

\author{
Dongil Seo, Young Bin Jeong, Kwang Ho Jeong, Hak Lae Lee ${ }^{\dagger}$ and Hye Jung Youn \\ Received July 2, 2013; Received in revised form July 24, 2013; Accepted July 30, 2013
}

\begin{abstract}
High loading of printing and writing grades with fillers has many advantageous aspects in papermaking because it allows decreasing fiber use and reducing manufacturing cost. High loading technology, however, has some disadvantageous aspects as well. It decreases physical properties of papers, especially strength properties. The problem associated with high loading can be reduced by applying surface sizing starch solution onto paper surface. It is important to control the penetration of the surface sizing starch solution into paper web to obtain the desired property improvement. In this study, the effect of the addition of two polymers into starch solution on paper properties has been examined. PVOH and polyDADMAC were used as polymeric additives for surface sizing with oxidized starch. Viscosity of starch solutions and surface roughness of dried starch films on glass slides showed that some interactions between polymeric additives and oxidized starch have been occurred and the most extensive interaction with starch solution was obtained with high molecular weight polyDADMAC. Low molecular weight PVOH was most effective in improving folding endurance and internal bond strength. On the other hand, polymer addition showed no effect on surface strength of paper. This indicates that not the level of starch holdout but the bonding strength of starch itself has predominant influence on surface strength of paper.
\end{abstract}

Keywords : Surface sizing, Oxidized starch, PVOH, PolyDADMAC, Polyelectrolyte complexes, Starch films, 3D images

- 서울대학교 농업생명과학대학 산림과학부 (Dept. of Forest Sciences, Seoul National University, Seoul, 151-921, Korea)

$\dagger$ 교신저자 (Corresponding Author) : E-mail : lhakl@snu.ac.kr 


\section{1. 서 론}

제지산업에서는 섬유 자원을 절감하고 생산비용을 줄이기 위해 하이로딩 기술에 많은 관심과 노력을 기울 이고 있다. 하이로딩 기술은 종이 내의 충전물 함량을 높이는 기술을 의미하며, 이를 통해 고가의 펄프원료 를 저렴한 충전물로 대체하는 것을 목표로 한다. ${ }^{1-2)}$ 그 동안 공정제어와 물성저하 등의 관련 문제점으로 인해 개념과 이론에만 머물러 있던 하이로딩 기술은 선응집 기술의 발전과 함께 국내 산업현장에서도 실제 적용되 는 단계까지 발전하고 있다. 비록 적절한 충전물 선응집 을 통해 인장강도 같은 여러 가지 강도가 급격히 감소하 는 현상을 완화할 수 있는 것으로 보고되고 있으나 ${ }^{3-4)}$ 여전히 충전물의 절대적인 함량 증가는 종이의 물성을 크게 저하시킬 것으로 우려되고 있다. 종이의 물성 가 운데 두께방향의 강도 저하는 인쇄 시 지분을 발생시키 는 등 여러 문제를 야기할 수 있으므로 고충전지의 제 조를 위해서는 이를 극복하기 위한 노력이 요망하다. 이러한 목적을 달성하기 위한 한 방법으로 지필의 표면 처리 즉, 표면사이징을 이용할 수 있을 것이다.

표면사이징은 건조된 지필 표면에 전분 호액을 도피 함으로써 종이의 강도를 향상시키고 표면 특성을 개선 하기 위해서 행해지는 공정을 말한다. ${ }^{5)}$ 표면사이징에 사용되는 전분 ${ }^{6}$ 중에서 화학변성전분은 변성전분제 조업체에서 산화제 등을 이용하여 음이온성 치환기를 도입하거나 분자량을 조절한 제품을 의미하는데, 물성 이 우수하여 제지산업에서 널리 이용되고 있는 전분의 하나이다. 산업 현장에서 변성이 이루어지는 다른 종 류의 전분도 대부분 음이온성 치환기를 도입한 산화전 분이므로 표면 사이징 공정에서 산화전분의 지필 내 침 투특성을 연구하는 것은 물성개선에 매우 큰 의미를 갖 는다.

그러나 가격이 저렴하여 널리 사용되고 있는 산화전 분은 표면잔류특성이 낮기 때문에 종이의 표면특성을 개선하는 데에 한계가 있다. ${ }^{6-8)}$ 이러한 산화전분의 단 점을 극복하기 위해서 고가의 양성전분을 사용하는 것 보다는, 산화전분에 양이온성 고분자전해질을 첨가하 는 방안이 더욱 경제적임에 착안한 연구도 다수 보고된 바 있다. ${ }^{6,9-11)}$ 예를 들어 Lee 등은 양이온성 PAM (polyacrylamide)을 산화전분 호액에 투입하는 경우 전 분 분자들이 종이 내부로 침투하기보다는 표면에 잔류한
다는 것을 CLSM(confocal laser scanning microscopy) 을 이용한 이미지를 통해 제시하고, 음전하를 띠는 섬 유와 양전하를 띠는 PAM 사이에 정전기적 인력이 발 생한 것이 그 이유라고 설명하였다. ${ }^{6)}$ 또, 표면에 주로 잔류하게 된 전분은 종이의 휨강성을 향상시키는데 효 과적임을 보고한 바 있다. ${ }^{10)}$ 양성고분자를 첨가한 표 면사이징이 도공지의 특성에도 영향을 미치는데, 양성 고분자는 도공층을 조기에 고정시켜 불투명도를 상승 시킨다는 보고도 있다. ${ }^{11)}$ 하지만 이들 연구는 표면사이 징 시 양이온성 첨가제에 의한 종이의 물성 변화를 집중 적으로 조사한 것으로서, 이들의 첨가에 따라 발생하는 고분자 물질의 응집현상에 대해서는 연구된 바 없다.

음이온성의 고분자전해질과 양이온성의 고분자전 해질이 용액상태로 혼합될 때에는 두 분자쇄가 서로 정 전기적으로 응집하여 덩치가 큰 고분자전해질 복합체 (polyelectrolyte complexes)를 형성한다. ${ }^{12)}$ 이러한 응집 에 따라 고분자복합체는 크기가 커짐과 동시에 가교나 링크를 형성하는 영역이 넓어지므로 탈수 향상제로도 우수한 성질을 나타낼 수 있다. ${ }^{13)}$ 동적광산란(dynamic light scattering) 분석기법을 이용하면 고분자 전해질 복합체의 크기를 평가할 수 있는데, 한 연구에서는 분 자량이 $15,000 \mathrm{Da}$ 인 양이온성의 poly-allylamine과 분 자량이 $5,000 \mathrm{Da}$ 인 음이온성의 polyacrylic acid가 복 합체를 형성할 경우 그 사이즈(z-average)가 40-130 $\mathrm{nm}$ 에 이르는 것으로 조사된 바 있다. ${ }^{14)}$ 고분자전해질 복합체의 사이즈를 측정하는 방법으로 nuclear magnetic resonance(NMR), atomic force microscopy(AFM)이 이용될 수도 있다. ${ }^{15)}$ 양이온성의 poly(amideamine) epichlorohydrin과 음이온성의 carboxymethylcellulose (CMC) 복합체의 직경은 $10-200 \mathrm{~nm}$ 의 분포를 갖는다 고 보고된 바 있다. ${ }^{15)}$ 이렇게 제조된 고분자전해질 복 합체는 종이의 인장강도를 향상시키는 효과가 우수하며, ${ }^{16)}$ 고분자전해질 다층박막(polyelectrolyte multilayers)과 비 교했을 때 고분자 흡착량 대비 종이 물성 개선의 효과 가 큰 것으로 보고되고 있다. ${ }^{14)}$

이러한 연구결과는 음이온성의 산화전분과 양이온 성 고분자첨가제가 함께 사용될 경우에도 고분자복합 체를 형성할 것임을 예측하게 하며, 이들은 응집체를 형성함으로 인해 지필 내부로의 침투성을 저하시키나 표면처리의 균일성에 부정적인 영향을 미칠 것이라 예 측할 수 있다. 따라서 고분자전해질에 의해 형성되는 
고분자복합체의 특성과 이에 따른 종이의 물성변화를 연구하는 것은 지금까지의 연구에서 간과되었던 영역 에 대한 해답을 제공할 것으로 생각한다.

$\mathrm{PVOH}$ 는 필름 형성 능력이 우수하고 섬유와 충전물 을 잘 결합시켜 바인더로 이용되는 ${ }^{17)}$ 한편 평활도, 표 면강도, 인장강도, 파열강도, 내절도를 향상시키는 능 력도 우수한 것으로 보고되고 있다. ${ }^{18)}$ 또한, 미세분을 고정하고, 충전물이 섬유에 흡착하는 것을 도와주기 때 문에 인쇄 시 발생할 수 있는 픽킹과 더스팅을 크게 줄일 수 있어, ${ }^{19)}$ 표면사이징에 적용할 때에도 강도개선 효과 를 나타낼 것으로 기대된다. 반면에 PolyDADMAC은 전하밀도가 매우 높은 양이온성의 선형 고분자전해질 로 음이온성의 산화전분과 강력하게 결합하여 고분자 복합체를 형성할 것으로 추정되며, 이들 복합체가 음전 하를 띠는 섬유와 만났을 때에도 양이온성을 띤 고분자 복합체가 강하게 섬유표면에 결합하여 종이 공극을 통 해 내부로 침투하는 정도가 낮을 것으로 기대된다.

본 연구의 목적은 하이로딩 기술의 발전으로 종이의 회분함량이 높아짐에 따라 상대적으로 약화될 수 있는 종이의 물성 저하를 억제할 수 있는 방안으로 전분 호 액에 고분자첨가제를 활용함으로써 표면사이징 효과 를 증대시킬 수 있는지의 가능성을 구명하기 위한 것이 다. 본 연구에서는 산화전분 호액에 대한 고분자 첨가 제로 PVOH(poly-vinyl alcohol)와 polyDADMAC (polydiallyldimethylammonium chloride)을 사용하 고, 산화전분과 이들 고분자에 의해 형성되는 사이즈 필름의 형태를 관찰하고, 사이징 처리에 따른 종이 물 성의 변화를 조사하였다.

\section{2. 재료 및 방법}

\section{1 공시재료}

표면사이징용 호액 제조를 위한 전분으로는 삼양제 넥스에서 생산한 산화전분(Oxidized starch) C-3010 을 사용하였다. 전분 호액에 첨가한 고분자는 $\mathrm{PVOH}$ 와 polyDADMAC으로 Sigma Aldrich에서 구입하여 사용하였다. 실험에 사용한 $\mathrm{PVOH}$ 와 polyDADMAC 의 분자량과 전하밀도를 Tabel 1에 나타내었다. $\mathrm{PVOH}$ 는 $98 \%$ 가수분해된 것을 분자량이 다르게 2 종을 사용 하고, $95^{\circ} \mathrm{C}$ 에서 20 분간 용해하여 용액의 농도가 5
Table 1. Molecular weight and charge density of polymenic additives

\begin{tabular}{lcc}
\hline \multicolumn{1}{c}{ Type } & $\begin{array}{c}\text { Molecular weight, } \\
\text { g/mol }\end{array}$ & $\begin{array}{c}\text { Charge density, } \\
\text { meq/g }\end{array}$ \\
\hline \multirow{2}{*}{ PVOH } & $\begin{array}{c}13,000-23,000 \\
146,000-186,000\end{array}$ & nonionic \\
& $146,0 \ldots \ldots \ldots \ldots \ldots \ldots \ldots \ldots \ldots$ \\
PolyDADMAC & $-100,000$ & +6.2 \\
& $400,000-500,000$ & \\
\hline
\end{tabular}

wt.\%가 되도록 준비하였다. PolyDADMAC도 분자량 이 다른 2종을 $\mathrm{PVOH}$ 와 마찬가지로 $5 \mathrm{wt} . \%$ 농도의 용 액으로 준비하여 사용하였다. 무림피앤피에서 생산한 회분 함량 $22 \%$ 의 백상지를 표면 사이징 기질로 사용하 였다. 평량은 $68 \mathrm{gsm}$ 으로 표면사이징 처리를 하지 않 은 것을 사용하였다.

\section{2 실험 방법}

\subsection{1 사이즈제의 제조}

산화전분 $50 \mathrm{~g}$ 을 $500 \mathrm{~mL}$ 비커에 넣고 히팅맨틀 (MS-DMB, Mtops, Korea)을 이용하여 $95^{\circ} \mathrm{C}$ 에서 30 분간 호화하였다. 호화가 끝난 전분 호액을 식히면서 $70^{\circ} \mathrm{C}$ 가 되면 고분자 첨가제를 전분 대비 $5 \mathrm{pph}$ 투입하 고, 30분간 교반하였다. 그 후 증류수를 이용하여 사이 즈제의 고형분 함량이 $10 \mathrm{wt} . \%$ 가 되도록 조절하였다. $1 \mathrm{~N}$ 의 수산화나트륨을 몇 방울 투입하여 사이즈제의 $\mathrm{pH}$ 를 8로 조절하였다. 고분자 첨가제를 투입하고 $\mathrm{pH}$ 를 조절한 후, 사이즈제의 최종 온도가 $50^{\circ} \mathrm{C}$ 가 되도록 준비하고 $400 \mathrm{rpm}$ 으로 교반하였다. Brookfield 점도 계를 이용하여 $50^{\circ} \mathrm{C}$ 의 사이즈제 점도를 $100 \mathrm{rpm}$ 에서 측정하였다. 사이즈제를 $0.01 \mathrm{wt} \%$ 로 희석한 다음 particle charge detector(PCD-03, Mütek, Germany)를 이용하여 현탁액의 전하 요구량을 측정하였다.

\subsubsection{3차원 표면 형상 관찰}

크기가 $75 \times 25 \times 1 \mathrm{~mm}$ 인 슬라이드 글라스(Marienfeld, Germany)에 사이즈제를 코팅하고 사이즈 필름의 형 상을 관찰하였다. 먼저 슬라이드 글라스 표면의 유기 물질을 제거하고, 표면을 섬유와 같이 친수성으로 만 들기 위해 피라냐 용액(Piranha solution)으로 세척하 였다. 피라냐 용액은 황산(98\%, Junsei, Japan)과 과산 화수소(34\%, Junsei, Japan)를 3:1로 혼합하여 제조하 


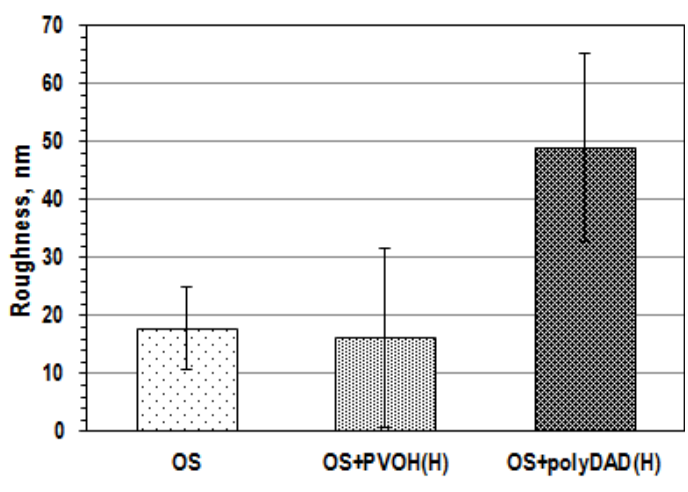

Fig. 1. Arithmetic average roughness of the starch films coated on glass slides.

였다. 이 용액에 슬라이드 글라스를 30 분간 담가 유리 표면의 유기물질을 제거하고, 증류수가 담긴 초음파 세척기로 슬라이드 글라스를 옮겨 각 5분간 6번 헹구 어내고 상온에서 건조시켰다.

앞서 제조한 사이즈제는 $50^{\circ} \mathrm{C}$ 를 유지하며 $400 \mathrm{rpm}$ 으로 교반시켰다. 이 사이즈제에 슬라이드 글라스를 20 초간 담갔다 뺀 후, 움직이지 않도록 고정시켜 $105^{\circ} \mathrm{C}$ 오븐에 넣고 8시간 동안 충분히 건조시켰다.

비접촉 3차원 미세 형상 측정기(Nano View-E1000, Nano System, Korea)를 이용하여 필름 표면 5곳의 러 프니스를 측정하였다. 이 기기는 복수의 간섭 신호영 상을 획득한 후 화소에서 발행하는 간섭 신호의 위상을 계산함으로써 높이를 측정하는 원리를 가지고 있다. 광원으로 할로겐램프를 사용하였고, 배율 $\times 10$ 의 렌즈 를 사용하였다. 소프트웨어(NanoMap, Nano system, Korea)를 이용하여 러프니스와 3차원 이미지를 얻었다.

\subsection{3 표면 사이징 및 종이 강도 측정}

실험실용 바코터(Auto Bar Coater, GIST, Korea)와 5 번 $\operatorname{rod}$ 를 이용하여 양면을 사이징하였다. 한 면에 사 이징을 실시하고 $120^{\circ} \mathrm{C}$ 로 예열한 에어 드라이어에서 2
분간 건조시킨 다음, $120^{\circ} \mathrm{C}$ 의 실린더 드라이어로 1 분 간 건조시켜 종이가 비교적 평탄하도록 하였다. 이때 한 면의 픽업량은 $1.6 \mathrm{~g}$ 으로 측정되었다. 다른 면에 대 해서도 같은 순서로 작업을 하고, 사이징 처리한 종이 를 온도 $25^{\circ} \mathrm{C}$, 상대습도 $50 \%$ 인 조건에서 24 시간 조습 처리하였다. 종이의 내부결합강도(Scott internal bond tester, Precision, USA)를 TAPPI test methods T 569 $\mathrm{pm}-00$ 에 따라 측정하였다. 표면강도를 평가하기 위해 $\mathrm{T} 459$ om-99를 따라 왁스 픽(Dennison waxes)과 픽킹 저항(RI tester, Akira, Japan)을 측정하고, T 423 cm-98 에 의거 내절도(Tinius Olsen, USA)를 측정하여 표면 사이징에 의한 물성 변화를 관찰하였다.

\section{3. 결과 및 고찰}

\section{1 고분자가 첨가된 사이즈제의 특성 및 3차 원 표면 이미지}

Table 2는 제조된 사이즈제의 점도와 전하 요구량을 보여준다. 고분자가 첨가되지 않은 산화전분 사이즈제 (OS)는 점도가 $9 \mathrm{cPs}$ 로 측정되었고, 음이온성을 나타 내며 $0.15 \mathrm{meq} / \mathrm{g}$ 의 전하 요구량을 갖는 것으로 나타났 다. 여기에 비이온성 고분자인 $\mathrm{PVOH}$ 를 넣었을 때는 사이즈제 내의 산화전분 비율이 줄어듦에 따라 이온성 이 다소 감소했을 뿐, 전하요구량의 변화는 크지 않았다. $\mathrm{PVOH}$ 의 분자량이 $13,000-23,000 \mathrm{~g} / \mathrm{mol}$ 로 작을 때 사 이즈제의 점도는 고분자가 첨가되지 않은 사이즈제와 차이를 보이지 않았으나, 분자량이 146,000-186,000 $\mathrm{g} / \mathrm{mol}$ 인 $\mathrm{PVOH}$ 를 투입했을 때는 사이즈제의 점도가 12 cPs로 증가하였다. 양이온성 고분자전해질인 polyDADMAC 은 $6.2 \mathrm{meq} / \mathrm{g}$ 의 높은 전하밀도를 가지며, 이것의 투입 에 의해 사이즈제의 전하 요구량은 큰 변화를 나타내었 다. 전분 대비 $5 \mathrm{pph}$ 의 polyDADMAC은 계 내에 존재 하는 물질의 표면 전하를 양이온성으로 변화시키기에

Table 2. Viscosity and charge demand of starch solutions containing polymeric additive

\begin{tabular}{ccc}
\hline Type & Viscosity, cPs at $50{ }^{\circ} \mathrm{C}, 100 \mathrm{RPM}$ & Charge demand, meq/g \\
\hline OS & 9 & -0.15 \\
OS+PVOH(Low) & 9 & -0.13 \\
OS+PVOH(High) & 12 & -0.14 \\
OS+polyDADMAC(Low) & 15 & +0.12 \\
OS+polyDADMAC(High) & 26 & +0.22 \\
\hline
\end{tabular}


충분한 양인 것으로 판명되었다. PolyDADMAC도 $\mathrm{PVOH}$ 와 마찬가지로 분자량이 큰 것을 투입했을 때 최 종 사이즈제의 점도가 높아지는 경향을 나타내었다.

Fig. 1은 슬라이드 글라스에 사이즈제를 코팅하여 제조한 필름의 중심선에서 측정한 평균 러프니스 $(\mathrm{Ra})$ 값을 나타낸다. 아무 처리하지 않은 슬라이드 글라스 의 평균 러프니스는 2-3 nm의 값을 갖는 것으로 나타났 다. 슬라이드 글라스를 산화전분 사이즈제에 담가 코 팅했을 때, 표면의 러프니스는 약 $18 \mathrm{~nm}$ 가 되었다. 일 반적으로 고분자전해질 복합체의 형성은 반대 이온을 나타내는 고분자전해질 사이의 정전기적 결합을 의미 하나, 사이징 첨가제로 $\mathrm{PVOH}$ 를 첨가시켰을 때에도 비 이온성의 $\mathrm{PVOH}$ 와 음이온성의 전분 분자는 반데르발 스 힘에 의해 조금이나마 복합체를 형성할 것으로 생각 하였다. 이를 통해 다소간의 응집이 발생하여 필름의 러 프니스가 상승할 것으로 기대했으나, 앞서 전하요구량 에 큰 영향을 끼치지 못했던 것처럼, 러프니스에도 별 차이를 나타내지 않았다. 그러나 polyDADMAC을 투 입한 경우에 있어서는 러프니스가 상승하였다. 고분자 량의 polyDADMAC을 첨가해 만든 사이즈 필름은 평 균 러프니스가 약 $50 \mathrm{~nm}$ 인 것으로 측정되었다. 이는 두 고분자가 형성할 수 있는 최대 크기의 복합체는 아닐지 라도 음이온성의 전분과 양이온성의 polyDADMAC 이 서로 결합하여 고분자전해질 복합체를 형성한다는 사실을 보여주는 것이다. Fig. 2에 비접촉 미세형상측 정기를 이용해 얻은 사이즈 필름의 3 차원 이미지를 나 타내었다. PolyDADMAC을 투입한 경우에 고분자전 해질 복합체가 형성되어 표면이 거칠어지는 것을 확인 할 수 있었다.

\section{2 표면 처리된 종이의 물성 변화}

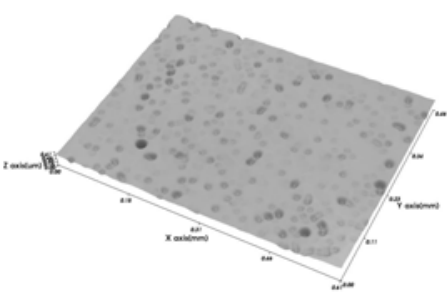

(A) OS

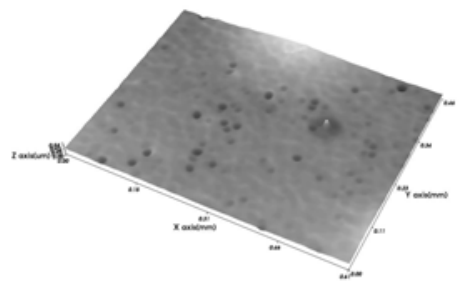

(B) $\mathrm{OS}+\mathrm{PVOH}(\mathrm{H})$

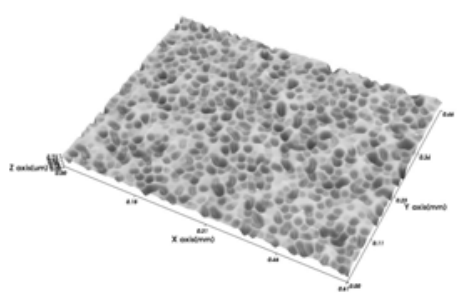

(C) OS+polyDADMAC(H)

Fig. 2. Topography of starch films coated on glass slides. Ra (A): $18.1 \mathrm{~nm},(B): 16.1 \mathrm{~nm},(C): 53.9 \mathrm{~nm}$. 


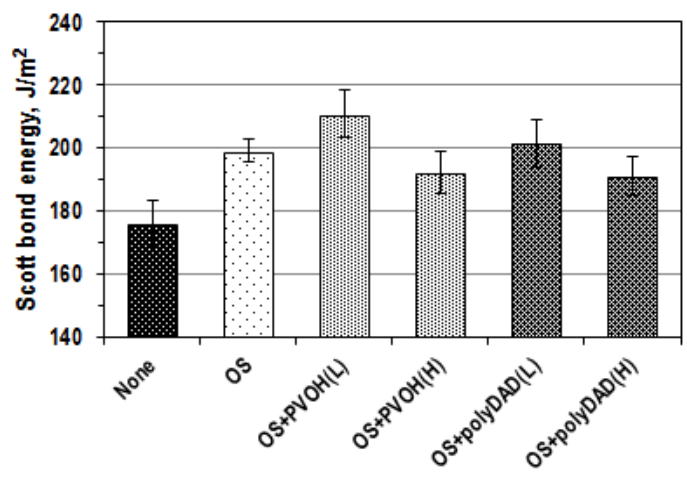

Fig. 3. Scott bond energy of sized paper with starch solutions.

지 못하였다. 고분자량의 고분자는 종이 내부로의 침투 가 불리하기 때문이라 판단된다. 또, polyDADMAC의 경우에는 표면에 양전하를 띠는 고분자전해질 복합체 를 형성하기 때문에, 사이징 처리 시 종이 내부로 침투 하기 보다는 표면에 고착되는 경향을 보이기 때문이다.

픽킹 저항을 판별하기 위해 드라이 픽 실험을 수행 하고 전사시킨 이미지를 Fig. 4에 나타내었다. Tack value 12 인 잉크를 메인 롤에 분산하고 회전시켜 종이 가 뜯기는 것을 확인하였다. 사이징을 하지 않은 샘플 은 픽킹이 발생했으나, 사이징 처리를 행한 시편은 메 인 롤을 5회 회전시킬 때까지 전혀 뜯기지 않았다. Tack value를 20으로 높여 실험했을 때도 메인 롤을 2회 순 환시키자 사이징 처리하지 않은 시편은 뜯기기 시작했 으나, 사이징 처리된 시편은 픽킹이 발생하지 않았다. Fig. 5에는 dennison wax를 이용해 critical wax strength

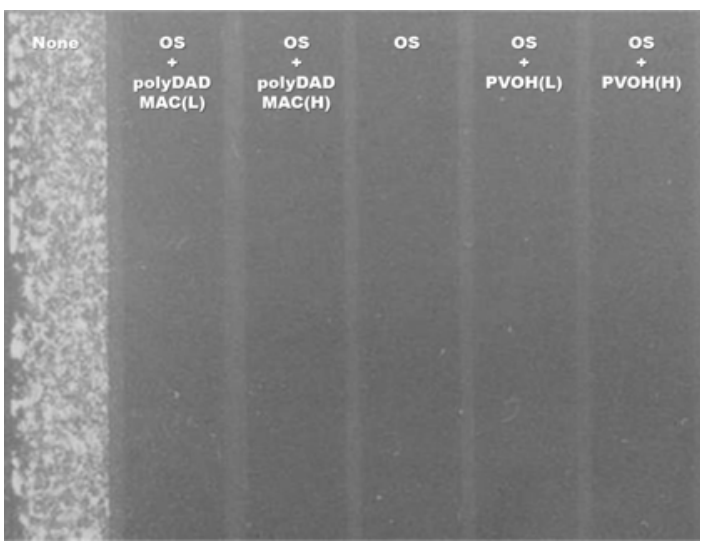

Fig. 4. Picking resistance of sized paper with starch solutions. number를 측정한 결과를 나타내었다. Critical wax strength number는 종이 샘플의 표면을 흐트러뜨리지 않는 왁스의 최댓값으로 나타낸다. 표면 사이징 처리 하지 않은 종이는 $9 \mathrm{~A}$ 왁스 막대를 사용할 때 블리스터 나 픽이 발생했고, 8A 막대를 사용한 경우에는 외양을 유지했기 때문에 wax strength number가 8로 측정되 었다. 표면사이징 처리한 경우에는 전분 호액에 첨가 된 고분자의 유무, 종류, 분자량에 관계없이 모두 16으 로 같은 값을 나타내었다. 고분자가 첨가되지 않거나 $\mathrm{PVOH}$ 가 첨가된 경우보다는 polyDADMAC이 첨가 된 경우가, 저분자량 보다는 고분자량의 고분자가 첨 가된 경우가 전분이 종이의 표면에 잔류하는 데 도움을 주어 표면강도를 향상시킬 것으로 예상했으나, 실제로 는 물성에 변화를 일으킬 만큼의 차이를 만들지 못한 것으로 판단된다. 표면사이징을 통해 표면강도를 향상 시키기 위해서는 고분자를 첨가하기보다는 강도 향상 에 유리한 전분을 선택하는 것이 합리적일 것으로 생각 한다. 양성전분은 필름형성이 좋을 뿐만 아니라, 양이 온성의 전하가 두께방향으로의 침투를 억제하여 표면 에 고착시키는데 도움을 주는 것으로 알려져 있다. ${ }^{6}$

고분자첨가제가 내부결합강도와 표면강도 외의 다 른 종이 물성 어떠한 영향을 미치는 지를 관찰하기 위 해 내절도를 측정하고 이를 Fig. 6에 나타내었다. $\mathrm{PVOH}$ 가 섬유와 충전물을 결합시키는 역할을 하는 것 과 더불어 $\mathrm{PVOH}$ 로 형성된 필름은 유연한 성질을 갖기 때문에, ${ }^{17)}$ 강도 향상에는 도움을 주지만 상대적으로 뺏뻣한 필름을 형성하는 전분보다는, ${ }^{5}$ 내절도를 향상

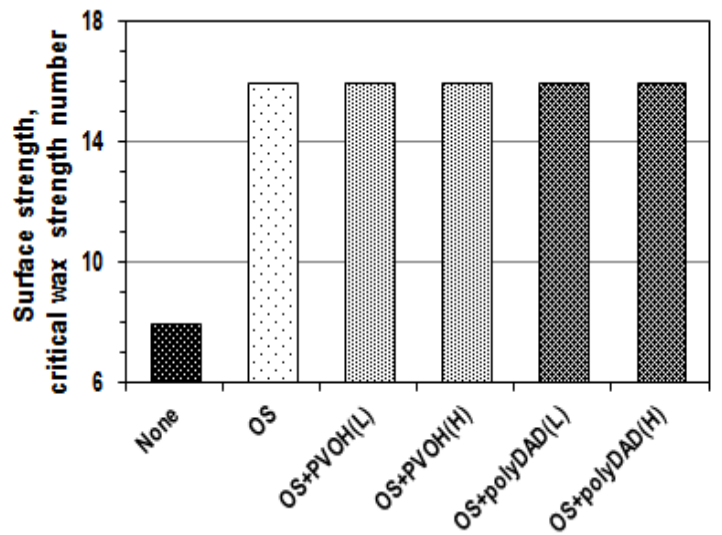

Fig. 5. Surface strength of sized paper with starch solutions. 


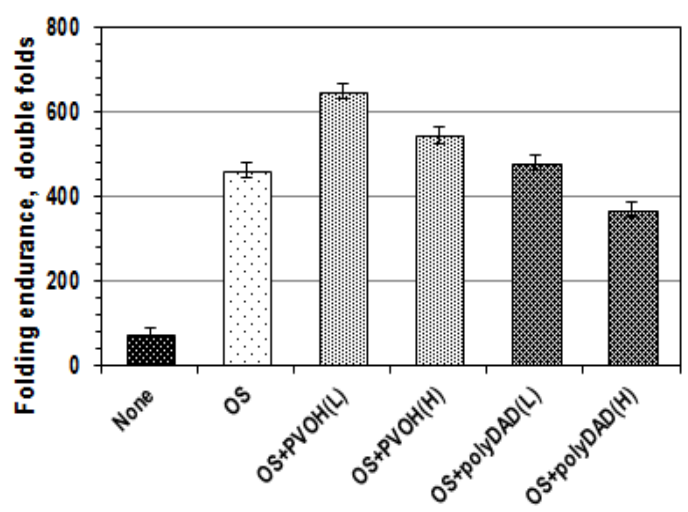

Fig. 6. Folding endurance of sized paper with starch solutions.

시키는 데 유리하였다. 분자량이 작을 때 내절도를 상 승시키는 효과가 컸던 이유는 고분자량인 경우에 비해 $\mathrm{PVOH}$ 가 두께 방향 전 범위에 걸쳐 고루 분포했기 때 문으로 여겨진다. PolyDADMAC을 투입한 경우에는 앞서 Fig. 3의 내부결합강도와 비슷한 결과를 나타내 었다. 저분자량의 polyDADMAC을 투입한 경우에는 기존과 거의 같은 값을 나타내었고, 고분자량의 고분 자를 투입했을 때는 강도가 떨어지는 결과를 나타내었 다. 전분과 polyDADMAC이 양이온성의 고분자전해 질 복합체를 형성하여 종이 내부로의 침투가 억제되는 것에 더하여 복합체를 구성하는 고분자 첨가제의 분자 량이 클 때 침투가 더욱 어려워지는 것으로 보인다.

\section{4. 결 론}

하이로딩 기술의 발전으로 종이의 회분함량이 높아 짐에 따라 상대적으로 약화될 수 있는 내부결합강도와 표면강도를 향상시킬 수 있는 방안으로 전분을 이용한 표면사이징을 선택하고, 호액에 고분자를 첨가하여 물 성 개선 효과를 향상시키고자 하였다. 산화전분 호액에 고분자 물질인 $\mathrm{PVOH}$ 나 polyDADMAC을 첨가하여 그 영향을 분석하였다. 고분자 첨가에 따른 사이즈제의 점도와 전하 요구량 변화를 측정하였다. 그 결과 분자량 이 약 $20,000 \mathrm{~g} / \mathrm{mol}$ 인 저분자량의 $\mathrm{PVOH}$ 는 점도와 전 하 요구량을 거의 변화시키지 않았고, polyDADMAC 은 전하를 양이온성으로 역전시켰다. 고분자량의 고분 자는 사이즈액의 점도를 상승시키는 결과를 보였다. 분
자량 $400,000 \mathrm{~g} / \mathrm{mol}$ 이상인 고분자량의 polyDADMAC 은 산화전분과 고분자전해질 복합체를 형성하여, 슬라 이드 글라스에 사이즈액으로 필름을 만들었을 때, 러 프니스를 증가시키는 결과를 나타냈다. 복합체의 크기 가 커지는 것은 전하가 양이온성으로 역전되는 것과 더 불어, 전분과 고분자가 종이 내부로 침투하는 것을 저 해하는 역할을 하는 것으로 판단된다. 표면사이징 처 리한 모든 샘플의 표면 강도가 높은 지점에서 같은 값 을 갖는 것으로 측정되어 사이즈제 조성 사이의 우위를 비교할 수 없었으나, 내부결합강도와 내절도의 경우에 는 분자량이 약 $20,000 \mathrm{~g} / \mathrm{mol}$ 의 작은 $\mathrm{PVOH}$ 가 강도를 향상시키는데 유리하게 작용하였다. 이는 종이 내부로 침투한 $\mathrm{PVOH}$ 가 미세분을 고정시키고, 충전물을 섬유 에 결합시켰기 때문으로 판단된다.

\section{사 사}

본 연구는 2012년도 지식경제부의 재원으로 한국에 너지 기술평가원(KETEP)의 지원을 받아 수행한 연구 과제입니다. (No.2010201010037A)

\section{Literature Cited}

1. Lee, K.H., and Lee, H.L., Preflocculation of GCC with cationic PAM and cationic starch and the influence of their dosage and shear rate on prefloc size, J. Korea TAPPI 38(4):1-9 (2006).

2. Lee, J., Ryu, J., Sim, K., Ahn, J.E., Lee, H.L., and Youn, H.J., Preliminary study on properties of Layerby-Layer assembled GCC with polyelectrolytes, J. Korea TAPPI 43(3):35-42 (2011).

3. Seo, D., Im, W.H., Youn, H.J., and Lee, H.L., The effects of process variables for GCC pre-flocculation on floc and handsheet properties, NPPRJ 27(2):382-387 (2012).

4. Im, W., Lee, H.L., Youn, H.J., and Seo, D., Structure characterization of ground calcium carbonate flocs by fractal analysis and their effects on handsheet properties, TAPPI J. 12(3):17-23 (2013).

5. Smook, G.A., Handbook for Pulp \& Paper Technologists, Angus wilde publications Inc., Vancouver, pp. 284-298 
(2002).

6. Lee, H.L., Shin, J.Y., Koh, C.H., Ryu, H., Lee, D.J., and Sohn, C.M., Surface sizing with cationic starch: its effect on paper quality and papermaking process, TAPPI J. 1(1):1-8 (2002).

7. Lee, C.J., and Shin, D.S., Effects of oxidized and cationic starch at the size press on sizing degree and strength properties of paper, J. Korea TAPPI 20(2): 5-16 (1988).

8. Yoon, J.Y., and Lee, Y.K., Studies on the application of starch for paper surface sizing, J. Korea TAPPI 34(2):1-12 (2002).

9. Seo, M.S., Lee, H.L., and Youn, H.J., Use of cationic PAM as a surface sizing additive to improve paper properties, Proceedings of 2006 Pan Pacific Conference, pp. 245-250 (2006).

10. Seo, M.S., Ahn, H.M., Youn, H.J., and Lee, H.L., Improvement of paper properties surface sized with the application of cationic PAM, Proceedings of Spring Conference of the KTAPPI, pp. 132-137 (2005).

11. Jun, D.G., and Lee, H.L., Effect of surface sizing with cationic polymer additives on the coating structure and coated paper properties, J. Korea TAPPI 40(1): 1-8 (2008).

12. Korhonen, M.H.J., Holappa, S., Stenius, P., and Laine J., Flocculation of fillers with polyelectrolye complexes, NPPRJ 28(2):239-247 (2013).
13 Xiao, L., Salmi, J., Laine, J., and Stenius, P., The effects of polyelectrolyte complexes on dewatering of ceullulose suspension, NPPRJ 24(2):148-157 (2009).

14 Ankerfors, C., Lingström, R., Wågberg, L., and Ödberg, L., A comparison of polyelectrolyte complexes and multilayers: their adsorption behavior and use for enhancing tensile strength of paper, NPPRJ 24(1):77-86 (2008).

15. Gärdlund, L., Wågberg, L., and Gernandt, R., Polyelectolyte complexes for surface modification of wood fibres: Influence of complexes on wet and dry strength of paper, Colloids and Surfaces A: Physicochem. Eng. Aspects 218:137-149 (2003).

16. Gärdlund, L., Norgren, M., Wågberg, L., and Marklund, A., The use of polyelectrolyte complexes (PEC) as strength additives for different pulps used for production of fine paper, NPPRJ 22(2):210-216 (2007).

17. Lamminmäki, T., Kettle, J., Puukko, P., Ketoja, J., and Gane, P., The role of binder type in determining inkjet print quality, NPPRJ 25(3):380-390 (2010).

18. Fatehi, P., and Xiao, H., The influence of charge density and molecular weight of cationic poly (vinyl alcohol) on paper properties, NPPRJ 23(3):285-291 (2008).

19. Hentzschel, P., Polyvinyl alcohol, In Pigment Coating and Surface Sizing of Paper, Lehtinen, E. (ed.), Finnish Paper Engineer's Association and TAPPI Press, Finland, pp. 277-287 (2000). 